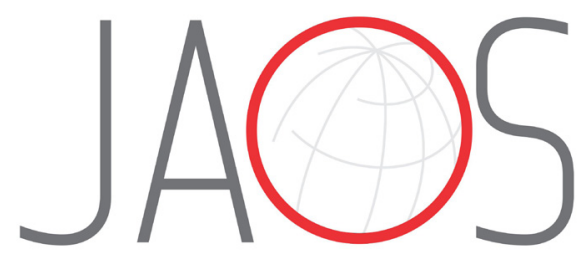

\section{Difference of brain-derived}

neurotrophic factor expression and pyramid cell count during mastication of food with varying hardness

\title{
Abstract
}

Jenny SUNARIANI ${ }^{1}$

Christian KHOSWANTO ${ }^{1}$

Wahyuning Ratih IRMALIA ${ }^{2}$
Submitted: April 10, 2018 Modification: August 30, 2018 Accepted: September 26, 2018

Corresponding address: Jenny Sunarian

Department of Oral Biology - Faculty of Dental Medicine - Universitas Airlangga - Jalan Prof. Dr. Moestopo No. 47 - Surabaya 60132 - Indonesia. Phone: +628123244881 / +62315030255 Fax +62 315020256 e-mail: jenny-s@fkg.unair.ac.id
Previous studies suggested that mastication activity can affect learning and memory function. However, most were focused on mastication impaired models by providing long-term soft diet. The effects of chewing food with various hardness, especially during the growth period, remain unknown. Objective: To analyze the difference of hippocampus function and morphology, as characterized by pyramidal cell count and BDNF expression in different mastication activities. Materials and Methods: 28-day old, post-weaned, male-Wistar rats were randomly divided into three groups $(n=7)$; the first (K0) was fed a standard diet using pellets as the control, the second (K1) was fed soft food and the third (K2) was fed hard food. After eight weeks, the rats were decapitated, their brains were removed and placed on histological plates made to count the pyramid cells and quantify BDNF expression in the hippocampus. Data collected were compared using one-way ANOVA. Results: Results confirmed the pyramid cell count $(K 0=169.14 \pm 27.25 ; K 1=130.14 \pm 29.32 ; K 2=128.14 \pm 39.02)$ and $B D N F$ expression $(K 0=85.27 \pm 19.78 ; K 1=49.57 \pm 20.90 ; K 2=36.86 \pm 28.97)$ of the $K 0$ group to be significantly higher than that of $K 1$ and $K 2$ groups $(p<0.05)$; no significant difference in the pyramidal cell count and BNDF expression was found between $K 1$ and $K 2$ groups ( $p>0.05$ ). Conclusion: A standard diet leads to the optimum effect on hippocampus morphology. Food consistency must be appropriately suited to each development stage, in this case, hippocampus development in post-weaned period.

Keywords: Hippocampus. Mastication. Pyramidal cell. BDNF.

'Universitas Airlangga, Faculty of Dental Medicine, Department of Oral Biology, Surabaya, Indonesia. ${ }^{2}$ Universitas Airlangga, Faculty of Dental Medicine, Surabaya, Indonesia. 


\section{Introduction}

Mastication is the process of crushing food and mixing it with saliva to form a bolus prior to swallowing, being a complex process involving the rhythmical opening and closing of the jaw, the secretion of saliva and tongue movement. ${ }^{1}$ Previous studies found correlation between mastication and the functions of other body parts aside from the digestive system. In addition to influencing nutritional intake, masticatory disorders have been proven to exert influence in increasing the risk of obesity and hyperglycemia, as well as impeding stress hormone regulation, learning processes and memory function. ${ }^{2}$ Mastication activity is critical as one of the sources of sensory input into the hippocampus. ${ }^{3}$ A decline in masticatory activity caused by a disorder can lead to hippocampal morphological changes, such as the decrease in pyramid cell count, in dendritic spines in cornu amonis-1 (CA1) and in proliferating cells in both the dentate gyrus and the astrocyte hypertrophy. ${ }^{4}$ Other studies also found that reduced muscle activity may decrease blood supply to the brain, thus impeding cerebral metabolism. ${ }^{5,6}$

The correlation between mastication activity and hippocampus morphology was identified from the neural pathway. Somatosensory input from the masticatory system may influence the hippocampus through synaptic projection from the thalamus and cerebral cortex. ${ }^{3}$ Brain Derived Neurotrophic Factor (BDNF) is fundamental in hippocampal learning and memory function. ${ }^{7}$ BDNF is a member of the neurotrophin family that promotes neuron survival, growth and plasticity, being abundantly found in the hippocampus. ${ }^{8}$

Previous studies observing the correlation between mastication, stress and cognitive function have proved that a long-term soft diet during the postweaning period could lead to learning and memory impairment. On the other hand, forced mastication in mice resulting from a hard diet can increase the proliferation and survival rate of neuron cells in dentate gyrus. ${ }^{7,9-12}$ In the growth period, the maturation of motoric function occurs during the maturation of the entire central nervous system, as well as of the morphological and functional maturation of the craniofacial complex. Newborn mammals obtain nutritional intake by sucking, which will later develop into a masticatory motion. Regarding rats, the first mastication movements were recorded on day 12 post-natal and completely developed between days 18 and $21 .{ }^{13}$ Nevertheless, the effects of mastication on learning and memory functions of the hippocampus, especially during the growth period, are not fully understood.

Based on a previous study by Irmalia, et al. ${ }^{14}$ (2017), spatial memory tests were conducted on 28day old, post-weaned rats after they had been fed food of varying hardness. The results confirmed that the standard diet group produced the best performance on a radial eight arm maze test, compared to the soft and hard diet groups. ${ }^{14}$ Thus, this study aims to analyze the differences of hippocampus function and morphology, through cellular and molecular examination of this under varying mastication activity. Based on the previous study, it is hypothesized that, providing a standard diet during the growth period will give the best response toward hippocampus morphology, compared to providing soft and hard diets.

\section{Material and methods}

\section{Ethical approval}

This study was approved by the Research Ethics Committee with certificate number 023/HRECC.FODM/ II/2017.

\section{Experimental design}

This was an analytic experimental study incorporating a post-test only control group design.

\section{Animal}

Twenty-one post-weaned, male Wistar Rats (Rattus novergicus), aged 28 days and weighing between 80 and 100 grams were purchased from stockbreeder Bintang Jaya (Surabaya, Indonesia). Sample size was calculated using Lemeshow's formula and based on the result of the previous study. ${ }^{14}$ Research subjects were randomly divided into three groups $(n=7)$ : a control group (KO) fed standard rodent chow (Gemuk A, PT. Japfa Comfeed, Jakarta, DKI Jakarta, Indonesia) (Nutritional content: water $12 \%$, protein $16 \%$, fat $7 \%$, fiber $8 \%$, calcium $1 \%$, and phosphor $0.8 \%$ ), a soft diet group (K1) fed powdered seed and grain and a hard diet group (K2) fed whole seed and grain (Hamsfood, Canada) (Nutritional content: protein $12 \%$, fat $7 \%$, fiber $10 \%$, calcium $0.20 \%$, phosphor $0.30 \%$, salt $0.08 \%$, manganese $55 \mathrm{mg} / \mathrm{kg}$, zinc $60 \mathrm{mg} /$ 
$\mathrm{kg}$, iron $70 \mathrm{mg} / \mathrm{kg}$, iodine $0.6 \mathrm{mg} / \mathrm{kg}$, selenium 0.07 $\mathrm{mg} / \mathrm{kg}$, vitamin A $7500 \mathrm{IU} / \mathrm{kg}$, and vitamin D3 1500 $\mathrm{IU} / \mathrm{kg}$ ); all groups were given $20 \mathrm{mg}$ food/day. Rats were acclimatized for seven days prior to treatment, subsequently being placed in a plastic cage containing wood shavings bedding covered with woven wire. They were kept at room temperature following a consistent 12-hour light-dark cycle. After eight weeks, the rats were euthanized through an anesthesia overdose and their brains were isolated.

\section{Histological examination}

Histological examination consists of pyramidal cell count and BDNF expression, which were done using a cell counter combined with manual counting in case a system error occurred. To prevent bias, the study outcome measurement was done by an expert in histology who was blind to group allocation.

\section{Pyramidal cell count}

Isolated brains were soaked in $10 \%$ neutral buffered formalin for two hours in individual pots. The brains were then immersed in formaldehyde, soaked for 24 hours and dehydrated using ethanol (at $70 \%$ concentration for 24 hours followed by $90 \%$ for 1 hour), rinsed using xylene and, finally, embedded in paraffin. A coronal section $(5 \mu \mathrm{m})$ was performed following the bregma $(-3.3 \mathrm{~mm}$ to $-3.8 \mathrm{~mm}$ posterior to the bregma) using a microtome (Accu-Cut SRM, Sakura, AJ Alphen aan den Rijn, Netherlands). ${ }^{15}$ The sectioned tissues were deparaffinized, placed on object glass and stained using hematoxylin eosin (HE). ${ }^{16}$ Pyramidal cell count was conducted using a light microscope (Nikon H600L, Melville, New York, USA) at 400x magnification. Cell count and pictures were taken of five different fields that were randomly chosen by the system ${ }^{17}$ using a 300-megapixel DS Fi2 digital camera and a Nikon Image System image processor (Nikon, Melville, New York, USA).

\section{BDNF expression}

Paraffinized brain tissue was cut into coronal sections following the bregma $(-3.3 \mathrm{~mm}$ to $-3.8 \mathrm{~mm}$ posterior to the bregma) using a $5 \mu \mathrm{m}$ thick microtome (Accu-Cut SRM, Sakura, AJ Alphen aan den Rijn, Southern Netherland, Netherland). Sectioned tissues were dipped in warm water $\left(20^{\circ}\right.$ to $\left.30^{\circ} \mathrm{C}\right)$, placed on a poly-L-Lysine object glass surface and dried on a hotplate. Each plate was soaked in Xylol I, II, III for 3 minutes and then in absolute alcohol I \& II for additional 3 minutes. Following, the plates were soaked in $96 \%, 90 \%, 80 \%, 70 \%$ alcohol for three minutes each, before being rinsed with running water for 5 minutes. After drying, the plates were immersed in hydrogen peroxide $\left(\mathrm{H}_{2} \mathrm{O}_{2}\right)$ for 5 to 10 minutes, then washed twice with phosphate buffer saline (PBS), each for 4 minutes. Drops of Ultra $V$ block were added for 5 minutes before being rinsed. Tissue staining was subsequently performed by adding rabbit anti-BDNF polyclonal antibody (Bioss, Woburn, Massachusetts, USA) for 60 minutes and washing with PBS twice for 4 minutes. Following, Biotinylated link drops (yellow) were added for 30 minutes and washed with PBS twice for 4 minutes. DAB (3,3 diaminobenzidine) chromogen (Sigma, St. Louis, Missouri, USA) was added for 6 to 10 minutes and washed with PBS twice for 4 minutes. Counterstain was performed using hematoxylin meyer and the sections were mounted. The slides were examined using a light microscope at 400x magnification. To count BDNF expression, pictures of five different fields were randomly chosen and taken using a DS Fi2 300-megapixel digital camera and an image processor. ${ }^{15}$

\section{Statistical analysis}

Collected data were analyzed using KolmogorovSmirnov test to find the distribution. Given that all variables were normally distributed, the resulting data were analyzed with the SPSS 16 software for Windows (SPSS Inc., Chicago, USA) using a one-way ANOVA test, and continued using Tukey's LSD test to find differences between each group. Results are presented as mean and standard deviation (SD). The significance level considered was 0.05 .

\section{Results}

Table 1 presents the results of pyramidal cell count and BDNF expression. Figure 1, which contains coronal section imaging of the hippocampus, shows

Table 1- Pyramid cell count and BDNF expression (Mean \pm SD). Means with different superscript letters are statistically significant (Tukey's LSD, $\mathrm{P}<0.05$ )

\begin{tabular}{ccc}
\hline Group & $\begin{array}{c}\text { Pyramid Cell } \\
\text { (mean } \pm \text { SD) }\end{array}$ & $\begin{array}{c}\text { BDNF Expression } \\
\text { (mean } \pm \text { SD) }\end{array}$ \\
\hline K0 & $169.14^{\mathrm{a}} \pm 27.25$ & $85.27^{\mathrm{a}} \pm 19.78$ \\
$\mathrm{~K} 1$ & $130.14^{\mathrm{b}} \pm 29.32$ & $49.57^{\mathrm{b}} \pm 20.90$ \\
$\mathrm{~K} 2$ & $128.14^{\mathrm{b}} \pm 39.02$ & $36.86^{\mathrm{b}} \pm 28.97$ \\
\hline
\end{tabular}



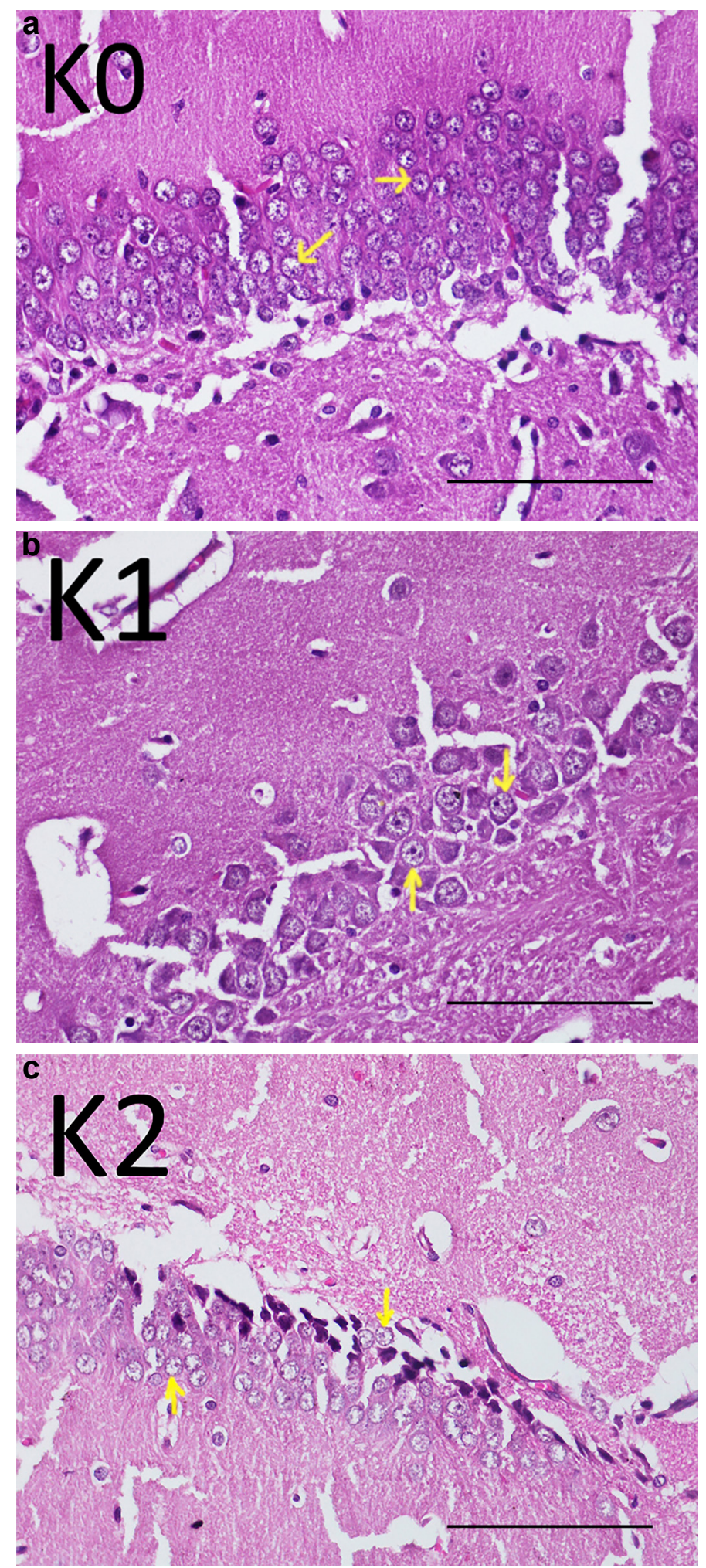

Figure 1- Hippocampus coronal section. Pyramid cells (arrow) of control group (K0) (a), soft diet group (K1) (b), and hard diet group (K2) (c)

that the control group had more pyramid cells in the hippocampus than the soft diet or hard diet groups. One-way ANOVA showed that there was a significant difference between the three groups $(p=0.049$; $r^{2}=0.285$ ). Pyramid cell count of the KO group was considerably higher when compared to those of $\mathrm{K} 1$ $(p=0.036)$ and $K 2(p=0.029)$ groups. Additionally, although $\mathrm{K} 1$ had more pyramid cells than $\mathrm{K} 2$, there was no significant difference $(p=0.909)$.

Regarding BDNF expression, observation results were similar to pyramid cell count results. BDNF expression in $\mathrm{KO}$ was higher than in $\mathrm{K} 1$ and $\mathrm{K} 2$ groups (Figure 2). The respective expression within groups was significantly different $\left(p=0.006 ; r^{2}=0.438\right)$. 

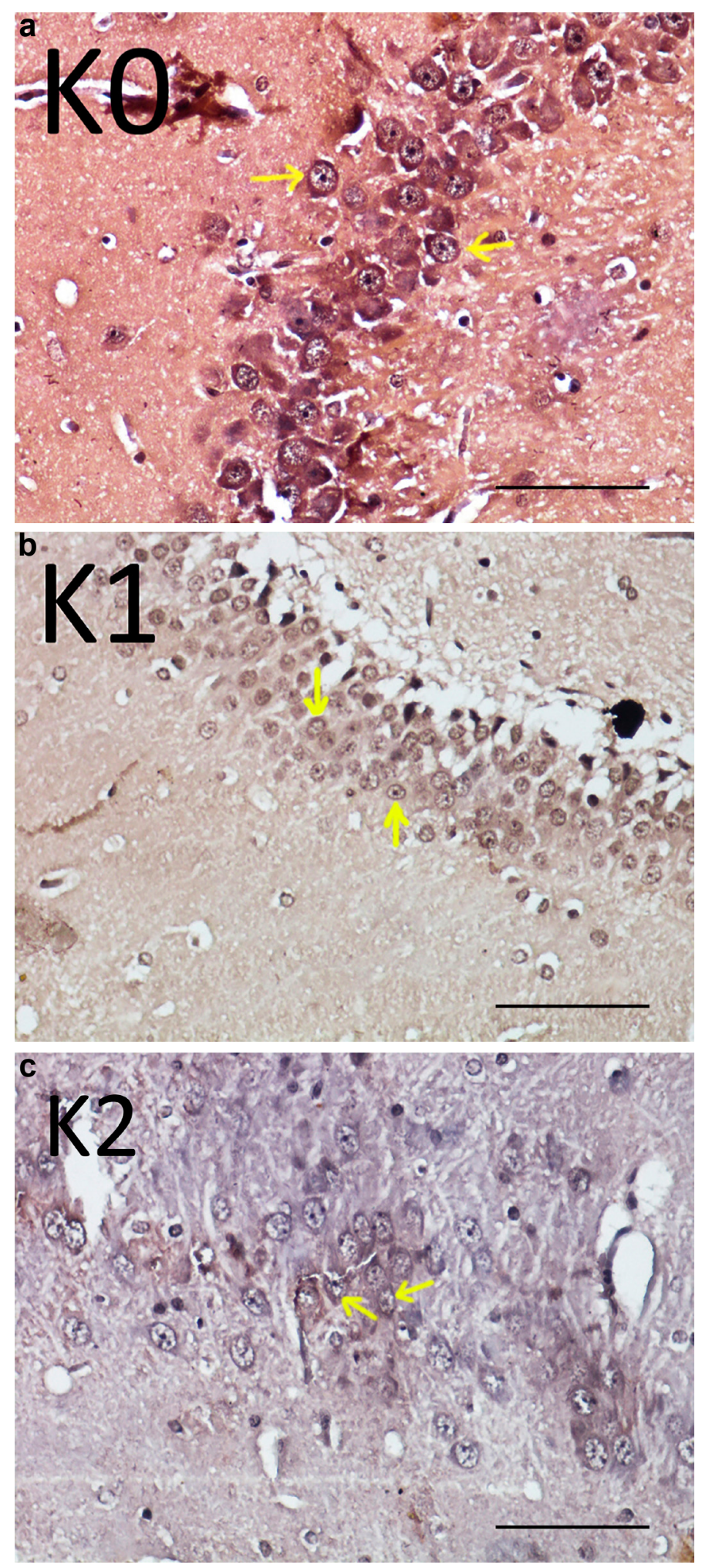

Figure 2- Hippocampus coronal section. Pyramid cells (arrow) that express BDNF (arrow) in K0 (a), K1 (b), and K2 (c)

BDNF expression in KO was significantly higher when compared to $K 1(p=0.017)$ and $K 2(p=0.002)$. Furthermore, BDNF expression in the $\mathrm{K} 1$ group was slightly higher than in the $\mathrm{K} 2$ group, but no significant difference between these groups $(p=0.326)$ was identified.

\section{Discussion}

This study was conducted using animal models with contrasting chewing habits to differentiate the respective masticatory intensities of each group. Postweaned rats were used to facilitate the examination of the response regarding different chewing intensities 
as rapidly as possible. Sensory input into periodontal mechanoreceptors, resulting from masticatory force, functions as a feedback mechanism in regulating muscle contraction. ${ }^{18}$ Previous studies have assessed hippocampus function in rats' growth based on the provision of food with varying hardness; thus, this research was performed to attest the results of the previous study by observing hippocampus function and morphology through cellular and molecular aspects. ${ }^{14}$

In this study, the $\mathrm{KO}$ group had the highest number of pyramid cells and greater BDNF expression when compared to the $\mathrm{K} 1$ and $\mathrm{K} 2$ groups. However, K2 showed higher results when compared to $\mathrm{K} 1$, was although with no significant difference. According to the results of this study, a long-term soft diet led the same results as that of a number of previous studies, which argued that a long-term soft diet may reduce pyramid cell counts and BDNF expression in the hippocampus. ${ }^{7,19}$ Interestingly, the hard diet group showed a different result from the previous study, which stated that enforced mastication can increase neuron survival and Neural Stem Cell (NSC) activity in the dentate gyrus of the hippocampus; thus, potentially increasing learning and memory function. ${ }^{12}$ However, the cited study was performed on older animals when compared to this study. The postweaned rats used in this study were in the transition period between suckling and using mastication for feeding. 20,21

The result obtained is in accordance with our previous one, which assessed hippocampus function using behavior tests. The study found that the normal diet group had the best performance in behavior tests, followed by soft diet and hard diet groups. This showed that behavior assessment may represent the histological structure of hippocampus. ${ }^{14}$ These findings also corroborate to another study by Okihara, et al.7 (2014), which found a memory impairment accompanied by low number of neuron cells in the hippocampus after long-term soft diet. ${ }^{7}$ Previous studies on mastication impaired animal models through tooth extraction ${ }^{22,23}$, bite-raise ${ }^{24,25}$ and long-term soft diets ${ }^{7,26}$ found that these aspects may alter hippocampus learning and memory function. Other studies also proved that impaired function of the hippocampus due to long-term soft diet could be improved by providing a hard diet. ${ }^{27,28}$ Therefore, mastication activity is critical in maintaining hippocampus function for learning and memory. ${ }^{29,30}$
Newborn rats obtain nutrition supplies from breast-feeding alone, without any other food or water, until they are 14 days old. The weaning process begins at that point, with the breast-feeding period being completely finished at 30 days of age. During the weaning period, the transition from suckling to mastication and an increase in the jaw closing muscle activity also occurs. Thus, firing frequency of the motor neuron within the jaw closing muscle will continuously intensify as newborns develop to prepare the muscle for the mastication process. ${ }^{20}$ Other studies also argued that physiological adaptation of an organ will increase with growth. Thus, it is possible that the response to different mastication loads will differ according to age. ${ }^{21}$ Given that the samples in this study were all in the transition period from suckling to chewing movement, we can assume that this is the main cause for the low pyramid cell count and BDNF expression in hippocampus of hard diet group. Rats in the transition period may need adaptation to chewing movements; thus, increasing the food hardness gradually is necessary according to growth requirements.

Mastication activity constitutes the combination of motor functions that consist of jaw, tongue, mouth and cheek movements. Such movement pattern changes continuously in response to sensory feedback from the oral cavity and is formed according to the hardness and texture of the digested food. Chewing activity in rats starts to develop at the end of the second postnatal week, when their teeth emerge, although not being dependent on the tooth emergence process. In rats, the mastication movement is controlled by the cerebral cortex, more specifically the Central Pattern Generator (CPG), located in the brain stem, on the other hand, the suckling movement does not require control from the CPG. ${ }^{31}$

Rats possess a circuit that controls the basic pattern of jaw movement within the mastication process, being located in the brain stem that belongs to the main trigeminal sensory nucleus (NVsnpr) and its dorsal section is expected to control masticatory rhythm. The neuron membrane in the dorsal section of NVsnpr will continue to grow during the first three postnatal weeks, especially during the transition period from suckling to chewing. Neuronal firing also occurs during this period. Immature neuron cells show superior adaptive and signaling ability in the first two postnatal weeks. ${ }^{13}$ 
The main limitation of this study was providing food of differing hardness but with the same nutritional content. Thus, this study used standard rodent chow, which is softer when compared to whole grain and seeds yet harder than powdered grain and seeds, as a control. However, the nutritional contents of each type are slightly different.

\section{Conclusion}

During the growth period, reduced mastication due to a soft diet and forced mastication resulting from a hard diet have been proven to reduce pyramid cell counts and BDNF expression in the hippocampus. A standard diet produced the optimum effect on the hippocampus. The degree of hardness of the food to be chewed should be well-suited to stages of development, in this case, hippocampus development in post-weaned period.

\section{Recommendation}

This study used different types of food with the control and treatment groups. Given the limitations of this study, to obtain a deeper understanding, further research using the same kind of food of various hardness is required.

\section{Conflicts of Interests}

The authors declare that they have no conflicts of interest.

\section{References}

1- Watanabe $\mathrm{Y}$, Hirano $\mathrm{H}$, Matsushita $\mathrm{K}$. How masticatory function and periodontal disease relate to senile dementia. Jpn Dent Sci Rev. 2015;51(1):34-40

2- Tsuchiya M, Niijima-Yaoita F, Yoneda H, Chiba K, Tsuchiya S, Hagiwara $Y$, et al. Long-term feeding on powdered food causes hyperglycemia and signs of systemic illness in mice. Life Sci. 2014;103(1):8-14.

3- Chen $H$, Iinuma $M$, Onozuka $M$, Kubo KY. Chewing maintains hippocampus-dependent cognitive function. Int J Med Sci. 2015;12(6):502-9.

4- Kubo K, Chen $\mathrm{H}$, Onozuka M. The relationship between mastication and cognition. In: Zhiwei W, editor. Senesence and senesence-related disorders. London: IntechOpen; 2013. p. 116-34.

5- Erickson KI, Voss MW, Prakash RS, Basak C, Szabo A, Chaddock L, et al. Exercise training increases size of hippocampus and improves memory. Proc Natl Acad Sci U S A. 2011;108(7):3017-22.

6- Chaddock-Heyman L, Erickson KI, Chappell MA, Johnson CL, Kienzler C, Knecht A, et al. Aerobic fitness is associated with greater hippocampal cerebral blood flow in children. Dev Cogn Neurosci. $2016 ; 20: 52-8$
7- Okihara H, Ito J, Kokai S, Ishida T, Hiranuma M, Kato C, et al. Liquid diet induces memory impairment accompanied by a decreased number of hippocampal neurons in mice. J Neurosci Res. 2014;92(8):1010-7. 8- Maass A, Düzel S, Brigadski T, Goerke M, Becke A, Sobieray U, et al. Relationships of peripheral IGF-1, VEGF and BDNF levels to exerciserelated changes in memory, hippocampal perfusion and volumes in older adults. Neuroimage. 2016;131:142-54.

9- Kubo KY, Ichihashi Y, Kurata C, Iinuma M, Mori D, Katayama T, et al. Masticatory function and cognitive function. Okajimas Folia Anat Jpn. 2010;87(3):135-40.

10- Sasaki-Otomaru A, Sakuma Y, Mochizuki Y, Ishida S, Kanoya Y, Sato C. Effect of regular gum chewing on levels of anxiety, mood, and fatigue in healthy young adults. Clin Pract Epidemiol Ment Heal. 2011;7:133-9. 11- Yamamoto T, Hirayama A, Hosoe N, Furube M, Hirano S. Effects of soft-diet feeding on BDNF expression in hippocampus of mice. Bull Tokyo Dent Coll. 2008;49(4):185-90.

12- Akazawa $Y$, Kitamura $T$, Fujihara $Y$, Yoshimura $Y$, Mitome $M$, Hasegawa T. Forced mastication increases survival of adult neural stem cells in the hippocampal dentate gyrus. Int J Mol Med. 2013;31(2):30714.

13- Ferraz-Pereira KN, Silva AR, Verdier D, Toscano AE, Lacerda DC, Manhaes-de-Castro $\mathrm{R}$, et al. Neonatal low-protein diet reduces the masticatory efficiency in rats. Br J Nutr. 2015;114(9):1515-30.

14- Irmalia WR, Sunariani J, Khoswanto C. Different food hardness affect memory. J Int Dent Med Res. 2017;10(3):987-90.

15- Kaler S, Dhar P, Bhattacharya A, Mehra RD. Preliminary morphological and immunohistochemical changes in rat hippocampus following postnatal exposure to sodium arsenite. Toxicol Int. 2013;20(2):160-9.

16- Amin SN, Younan SM, Youssef MF, Rashed LA, Mohamady I. A histological and functional study on hippocampal formation of normal and diabetic rats. F1000Res. 2013;2:151.

17- Han L, Ji Z, Chen W, Yin D, Xu F, Li S, et al. Protective effects of Tao-Hong-Si-Wu decoction on memory impairment and hippocampal damage in animal models of vascular dementia. Evid Based Complement Altern Med. 2015;2015:195835.

18- Türker KS, Sowman PF, Tuncer M, Tucker KJ, Brinkworth RS. The role of periodontal mechanoreceptors in mastication. Arch Oral Biol. 2007;52(4):361-4.

19- Ono $Y$, Yamamoto T, Kubo $K$, Onozuka M. Occlusion and brain function: mastication as a prevention of cognitive dysfunction. J Oral Rehabil. 2010;37(8):624-40.

20- Walcher DN., Peters DL, editors. Early childhood: the development of self-regulatory mechanisms. Pennsylvania: Pennsylvania State University; 1971.

21- Leong NL, Hurng JM, Djomehri SI, Gansky SA, Ryder MI, Ho SP. Age-related adaptation of bone-PDL-tooth complex: Rattus-Novergicus as a model system. PloS One. 2012;7(4):e35980.

22- Kawahata M, Ono Y, Ohno A, Kawamoto S, Kinomoto K, Onozuka $M$. Loss of molars early in life develops behavioral lateralization and impairs hippocampus-dependent recognition memory. BMC Neurosci. 2014;15:4.

23- Hioki Y, Iinuma M, Kurata C, Ichihashi Y, Tamura Y, Kubo K. Effects of early tooth loss on the hippocampus in senesence-acclerated mice. Pediatr Dent J. 2009;19(2):196-205.

24- Yamada K, Ono Y, Kubo K, Yamamoto T, Onozuka M. Occlusal disharmony transiently impairs learning and memory in the mouse by increasing dynorphin A levels in the amygdala. Tohoku J Exp Med. $2013 ; 230(1): 49-57$

25- Ekuni D, Endo Y, Tomofuji T, Azuma T, Irie K, Kasuyama K, et al. Effects of apoE deficiency and occlusal disharmony on amyloid-beta production and spatial memory in rats. PLoS One. 2013;8(9):e74966. 
26- Tsutsui K, Kaku M, Motokawa M, Tohma Y, Kawata T, Fujita T, et al. Influences of reduced masticatory sensory input from soft-diet feeding upon spatial memory/learning ability in mice. Biomed Res. 2007;28(1):1-7.

27- Mendes FC, Almeida MN, Felicio AP, Fadel AC, Silva DJ, Borralho TG, et al. Enriched environment and masticatory activity rehabilitation recover spatial memory decline in aged mice. BMC Neurosci. $2013 ; 14(1): 63$.

28- Utsugi C, Miyazono S, Osada K, Sasajima H, Noguchi T, Matsuda $M$, et al. Hard-diet feeding recovers neurogenesis in the subventricular zone and olfactory functions of mice impaired by soft-diet feeding. PLoS One. 2014;9(5):e97309.
29- Azuma K, Zhou Q, Niwa M, Kubo KY. Association between mastication, the hippocampus and the HPA axis: a comprehensive review. Int J Mol Sci. 2017;18(8). pii:E1687.

30- Iinuma M, Kondo H, Kurahashi M, Ohnishi M, Tamura Y, Chen H, et al. Relationship between the early toothless condition and hippocampal functional morphology. Anat Physiol. 2014;4(3):8-13.

31- Westberg KG, Kolta A. The trigeminal circuits responsible for chewing. Int Rev Neurobiol. 2011;97:77-98. 